\section{Student Anxiety and Perception of Difficulty Impact Performance and Persistence in Introductory Biology Courses}

\author{
Benjamin J. England, ${ }^{+*}$ Jennifer R. Brigati, ${ }^{\ddagger}$ Elisabeth E. Schussler, ${ }^{\S}$ and \\ Miranda M. Chen \\ 'Division of Biology and \$Department of Ecology and Evolutionary Biology, University of \\ Tennessee, Knoxville, TN 37996; 'Department of Biology, Maryville College, Maryville, TN 37804
}

\begin{abstract}
Students respond to classroom activities and achievement outcomes with a variety of emotions that can impact student success. One emotion students experience is anxiety, which can negatively impact student performance and persistence. This study investigated what types of classroom anxiety were related to student performance in the course and persistence in the major. Students in introductory biology classes self-reported their general class, test, communication, and social anxiety; perceived course difficulty; intention to stay in the major; and demographic variables. Final course grades were acquired from instructors. An increase in perception of course difficulty from the beginning to the end of the semester was significantly associated with lower final course grades $(N=337)$, particularly for females, non-Caucasians, and students who took fewer Advanced Placement (AP) courses. An increase in communication anxiety slightly increased performance. Higher general class anxiety at the beginning of the semester was associated with intention to leave the major $(N=122)$ at the end of the semester, particularly for females. Females, freshmen, and those with fewer AP courses reported higher general class anxiety and perceived course difficulty. Future research should identify which factors differentially impact student anxiety levels and perceived difficulty and explore coping strategies for students.
\end{abstract}

\section{INTRODUCTION}

Emotions are human reactions to future, current, and past events, and are a constant presence in academic classrooms (Pekrun, 1992; Mazer, 2017). These course-related emotions can be beneficial by promoting actions or reflections that increase student motivation, learning, and performance (Kim and Pekrun, 2014). However, not all emotions have positive impacts on student success. Positive emotions experienced by university students include enjoyment, interest, hope, and pride, while negative emotions can be anger, anxiety, frustration, and boredom (Pekrun and Stephens, 2010). Anxiety has been of interest to undergraduate education researchers in recent years because of the increasing prevalence of this emotion in students (Bitsko et al., 2018; Castillo and Schwartz, 2013) and student reports of anxiety associated with active-learning pedagogies in undergraduate science classrooms (Broeckelman-Post et al., 2016; England et al., 2017; Cooper et al., 2018).

Pedagogical approaches at the postsecondary level have been undergoing a transformation, including a noticeable shift toward the implementation of empirically validated teaching practices in science, technology, engineering, and mathematics (STEM) classrooms (Armbruster et al., 2009; American Association for the Advancement of Science [AAAS], 2011, 2015). This shift is not without cause: these teaching practices, including active-learning pedagogies, increase exam performance and lower course
Sarah L. Eddy, Monitoring Editor Submitted Dec 29, 2017; Revised Jan 18, 2019; Accepted Feb 6, 2019

CBE Life Sci Educ June 1, 2019 18:ar21

DOI:10.1187/cbe.17-12-0284

*Address correspondence to: Benjamin J. England (benglan6@utk.edu).

(c) 2019 B. J. England et al. CBE-Life Sciences Education (c) 2019 The American Society for Cell Biology. This article is distributed by The American Society for Cell Biology under license from the author(s). It is available to the public under an Attribution-Noncommercial-Share Alike 3.0 Unported Creative Commons License (http:// creativecommons.org/licenses/by-nc-sa/3.0). "ASCB®" and "The American Society for Cell Biology $® "$ are registered trademarks of The American Society for Cell Biology. 
failure rates on average (Springer et al., 1999; Freeman et al., 2007, 2011, 2014; Armbruster et al., 2009; Haak et al., 2011). The use of active-learning pedagogies has also been suggested as a mechanism to improve student persistence in STEM undergraduate majors (Graham et al., 2013). These results are encouraging, because fewer than $40 \%$ of freshman STEM majors persist to earn a STEM degree, yet the President's Council of Advisors on Science and Technology (PCAST; 2012) projected the need for an additional one million STEM graduates over the next decade.

The use of active learning typically comes with the expectation that students will respond in electronic, verbal, and/or written formats to questions that the instructor provides. For some students, the expectation to respond (and potentially be judged on that response) is associated with feelings of anxiety (Cooper et al., 2018). Students, for example, have reported anxiety associated with cold calling (Broeckelman-Post et al., 2016). While students liked that this practice encouraged them to pay attention, they did not enjoy having the spotlight on them, and the use of this practice discouraged some students from attending class on non-exam days. England et al. (2017) found that students in introductory biology reported different average levels of anxiety for different active-learning practices; responding to verbal questions produced higher average anxiety than group work or clicker questions. Average levels of student general class anxiety were higher with lower student self-reported letter grade, and student intention to persist in the major was associated with lower class anxiety levels (England et al., 2017). Active learning does not always increase student anxiety, however. Cooper et al. (2018) interviewed 52 students in large-enrollment courses and provided evidence that clicker questions and group work had the potential to either increase or decrease anxiety depending on teacher implementation and perceived benefit to the student, while random/cold call was always viewed negatively.

The current study focused on introductory biology courses at a large southeastern public research university that had incorporated active learning into its classrooms. Given the student reports of anxiety in these active-learning classrooms, we asked what types of anxiety might be related to student performance and persistence in these courses, at what times of the semester, and for which students in the classes. This research responds to a growing interest in understanding how undergraduate anxiety may impact motivation, performance, and persistence, particularly for demographic subsets of students (Bledsoe and Baskin, 2014; Eddy et al., 2014, 2015a,b; Broeckelman-Post et al., 2016; Cooper and Brownell, 2016; Cooper et al., 2018). Performance and/or persistence differentials have been observed between different genders (Eddy et al., 2014; Eddy and Brownell, 2016), ethnicities (Eddy and Hogan, 2014), and those who completed different numbers of Advanced Placement (AP) courses (Ackerman et al., 2013). These demographic groups were of particular interest to this study.

\section{Theoretical Framework}

This study used the control-value theory of achievement emotions (Pekrun, 2006; Pekrun et al., 2007) as the framework for the investigation. This theory proposes that students appraise the value of their achievement, and their perception of the control they have over their achievement, as antecedents to the emotions they feel in the classroom. Emotional feelings can be prospective (in anticipation of an activity or outcome) or retrospective (after the activity or outcome occurred) or can be related to activities currently occurring in the class. The emotions are termed "achievement emotions," because they are student responses to their perceptions of being judged on their performance in the class.

Achievement emotions have cascading impacts on student achievement through their interaction and influence on cognition and metacognition (Zeidner and Matthews, 2005; Grossberg, 2009; Bledsoe and Baskin, 2014), motivation (Kim and Pekrun, 2014), and engagement (Pekrun and Linnenbrink-Garcia, 2012). Achievement outcomes feed back to the student perceptions of control and value, which are themselves impacted by factors such as class curriculum and context, past educational performance, coping strategies, and genetic emotional predisposition (Pekrun, 2006). Instructor communication practices in particular have been strongly linked with student emotional responses in the classroom (Mazer, 2013), including increased student anxiety when instructors are rated lower in immediacy (closeness between teacher and students), clarity, and communication skills (Mazer et al., 2014).

Anxiety is a negative, prospective emotion that students experience when they are worried about failure (value) and feel only partially certain about their ability to control the outcome (Pekrun et al., 2007). Despite its assignment as a negative emotion, anxiety is also considered an activating emotion in terms of its impact on student interest and motivation (in contrast, hopelessness is an example of a deactivating emotion). Therefore, although the impact of anxiety is generally negative on average, its outcome varies by individual students based on their interest and motivation levels (Pekrun et al., 2007).

Several studies have revealed lower student performance associated with higher anxiety (Zusho et al., 2003; Akgun and Ciarrochi, 2010; England et al., 2017); however, students with midlevel anxiety earned the highest exam scores in a statistics course (Keeley et al., 2008). This follows the Yerkes-Dodson law (Yerkes and Dodson, 1908), which shows a bell curve-type relationship between anxiety and performance, with very low and very high anxiety impeding performance, but midrange anxiety heightening performance.

Anxiety can also be related to persistence. England et al. (2017) identified a difference between the average general class anxiety levels of undergraduate students who intended to stay in or leave the biology major, with those intending to leave having higher anxiety. Witt et al. (2014) found that receiver apprehension (students' fear that they may not be able to understand the presented material) was negatively associated with the intent to persist in students' respective majors. A study of 883 undergraduates at a STEM-focused German university reported that increased student anxiety was related to intent to drop out, but not to academic achievement (Respondek et al., 2017). In a study on course climate, Barthelemey et al. (2015) found that academic stress was negatively related to persistence (stress has the same physiological reactions as anxiety, but the cause of the reaction is considered more specifically identifiable [Endler and Parker, 1990]; however, stress and anxiety are very closely related). 
Just as anxiety can differ by individual, anxiety also differs among demographic subsets of students in academic environments. The most widely studied differences have been between females and males, with females having consistently higher anxiety then males (Misra and McKean, 2000; Bayram and Bilgel, 2008; Bryant et al., 2013). Anxiety is also higher in freshmen compared with upper-level students (Bayram and Bilgel, 2008). Anxiety in terms of underrepresented minorities has been studied in the context of stereotype threat (Steele and Aronson, 1995), in which invoking membership in a group with a negative stereotype causes lower student performance compared with peers. This effect is hypothesized to be mediated by increased anxiety among these students (Steele et al., 2002).

\section{Study Rationale}

Given the increasing prevalence of anxiety among undergraduates (Castillo and Schwartz, 2013) and use of pedagogies that students say can either increase or decrease their class anxiety (Broeckelman-Post et al., 2016; England et al., 2017; Cooper et al., 2018), it is important to investigate any potential links between anxiety and student performance and persistence in introductory science courses. As stated in multiple national reports (AAAS, 2011; PCAST, 2012), the retention of students in science is a priority for undergraduate education reform efforts. Investigations linking anxiety with persistence and performance in science, however, typically only use one measure of anxiety (such as general class anxiety), without probing other types of anxiety that may arise from active learning or assessment practices in today's increasingly complicated activelearning environments. Although a controlled design is needed to make clear connections between particular course practices and types of anxiety and student success, this study takes a first step by looking for relationships between different types of student anxiety, some of which may occur in response to active-learning pedagogies, and student performance and persistence in several introductory biology classes.

For this study, the specific types of anxiety that may be related to active-learning practices in undergraduate classrooms are communication anxiety and social anxiety (Zeidner and Matthews, 2005). We also examined test anxiety, because it has been a common type of anxiety investigated in relation to student performance (Culler and Holahan, 1980; Chapell et al., 2005). Communication anxiety in the classroom setting, known as classroom communication apprehension or participation anxiety, is a type of situational anxiety that occurs when students fear that they will perform inadequately in front of the instructor or their peers, such as when answering a question in front of the class (either by volunteering or in a cold-call response; Rocca, 2010; Karim and Shah, 2012). Classroom communication apprehension is fairly prevalent among undergraduates, with one study documenting that $70 \%$ experienced it at least once (Bowers, 1986). Social anxiety refers to the "marked and persistent fear of social or performance situations in which embarrassment may occur," and often manifests itself when students are expected to interact with others, for example, in classroom-based group work (Jefferson, 2001). A student with social anxiety would be expected to also suffer from classroom communication anxiety, but not all students who experience situational classroom communication anxiety have persistent social anxiety. Test anxiety is a fear of not performing well on assessments and is a commonly experienced anxiety in undergraduates. Gerwing et al. (2015) reported that $38.5 \%$ of undergraduates experience test anxiety at some point in their academic careers. Test anxiety is not limited to high-stakes exams-it has also been reported with low-stakes quizzes (Khanna, 2015). Measures of general class anxiety were also included to capture overall feelings of classroom anxiety that may have been different from specific anxieties that arose from particular classroom practices (e.g., questioning techniques or assessment style).

Prior research in our lab (England et al., 2017) indicated that general class anxiety levels differed for students who intended to stay in or leave the major and for those anticipating different final grades. Our work also indicated that students felt different levels of anxiety toward particular active-learning practices. This study builds on and expands this former work by testing the relationships between both general anxiety and a wider variety of anxiety measures and actual student performance and self-reported intention to persist. This allowed us to investigate the potential impact that student anxiety toward active learning could have on these student outcomes. We also deployed surveys at two time points during the semester to ask whether the timing of the anxiety matters, and we collected demographic information to ask whether certain subsets of students were more impacted by these anxieties than others. Thus, this new research asks three research questions:

1. Is student performance impacted by different types of initial anxiety and/or changes in these anxieties over the semester?

2. Is student persistence impacted by different types of initial anxiety and/or changes in these anxieties over the semester?

3. Do student subsets (e.g., different demographic groups) in the classes experience differential anxieties?

To answer these questions, we probed four types of student anxiety: general class anxiety, communication anxiety, social anxiety, and test anxiety. Identifying the types of anxiety that may impact performance and persistence for some students at certain times of the semester is critical to understanding student emotional experiences in undergraduate classrooms and developing potential interventions to promote student success.

\section{METHODS}

\section{Courses and Instructors}

Measurements of student anxiety, course performance, and persistence in the major were collected in Fall 2016 from students enrolled in majors' introductory biology lecture classes at a large southeastern public research university. The introductory biology sequence includes an Organismal and Ecological Biology (OEB) class and a Cellular and Molecular Biology (CMB) class that can be taken in either order. There were four OEB courses and three CMB courses offered in the Fall semester. The four OEB courses had enrollments of 214, 214, 221, and 70 students. The three CMB courses had enrollments of 221, 206, and 144 students. Students in each course were mostly freshmen and sophomore biology or pre-professional majors. Data were collected from all OEB and CMB courses offered in the Fall semester for a total of seven possible courses with seven separate instructors as sources of data. 
Each OEB and CMB class is structured as 2 hours of lecture per week and 1 hour of graduate teaching assistant-led smallgroup discussion. Students were prompted to only answer our survey questions about anxiety for the lecture portion of the class. Final grades included their performance in both the lecture $(75 \%$ of the grade) and the discussion (25\% of their grade). The introductory courses at this university used the main tenets of Vision and Change in Undergraduate Biology Education (AAAS, 2011) to guide their delivery, including the use of active-learning pedagogies. The lecture instructors of the courses all held PhDs in the relevant fields and were part of a community of instructors who met regularly to talk about course implementation.

All procedures for this study were approved by the human subjects review board at the University of Tenneessee, Knoxville, before the start of the research (IRB-16-03181-XP).

\section{Data Collection}

Data were collected through the use of two online surveys sent as links via an email from each course instructor. For each course (OEB and $\mathrm{CMB}$ ), surveys were disseminated at two points during the semester: an initial survey within the first month of the semester and a final survey at about week 14 of the semester. Surveys were disseminated by all instructors within a 24-hour period, so all students received access to the surveys within the same time frame. The initial survey dissemination was planned for week 4 to ideally have students complete it just before a first exam; however, classes had different exam schedules and some had quizzes, so a few courses may have had an assessment before students completed the survey. The final survey was given week 14 of the semester. This survey closed before the final exam period started, so all surveys were completed before course final assessments and with students having completed about $95 \%$ of the course. The total time for survey completion ranged from 10 to 15 minutes. Instructors offered their students an incentive to complete the surveys in the form of 1-3 bonus points (decided by the instructor) per survey the student completed. The total points in each class were 1000 .

Students' perceptions of their general class anxiety were captured through a seven-item, 7-point Likert-scale instrument adapted from Papanastasiou and Zembylas (2008) to measure anxiety levels toward research. The factor structure of this scale was delineated by Papanastasiou (2005). The scale was 7 points, with 1 being no anxiety and 7 being high anxiety. For this study, the word "research" in each item was replaced with the words "Biology lecture"; this was the only change made to the instrument. The seven items were as follows: "Biology lecture...makes me nervous, is stressful, makes me anxious, scares me, is complex, is complicated, is difficult" (Supplemental Table 1).

To assess the validity of this scale on our population, factor analyses were performed. Partial confirmatory factor analysis on the general class anxiety scale resulted in a best-fit solution of two factors: one for general class anxiety (four items), and one for perceived difficulty (three items). Full factor analyses results are reported in Supplemental Tables 2 and 3. This two-factor solution is noteworthy, as it conflicts with the proposed factor solution reported in Papanastasiou (2005); this could be explained by the different population of our sample or because students perceive anxiety toward research as different from anxiety toward a class.

Perception of difficulty and general class anxiety should be related via the "control" antecedent to anxiety as described in the control-value theory of achievement emotions (Pekrun, 2006). To make judgments about control, students would assess the demand that the class is placing on them (its perceived difficulty) and the resources that they have to meet that demand, which would then lead to emotional outcomes like anxiety. Because of the close theoretical relationship between perceived difficulty and anxiety, we retained the perceived difficulty measure for this study, but acknowledge that perception of difficulty is not a measure of anxiety.

Student responses to the first four items were averaged to arrive at a mean general class anxiety score for each student; student responses to the final three items were averaged to arrive at a mean perceived difficulty score for each student. Mean scores ranged from 1 to 7 : the higher the mean, the higher the anxiety or difficulty. The researchers use the word "general" to indicate that the anxiety measure was not specifically in response to any one aspect of the course, but instead a measure of overall perception of anxiety in the course.

Also included were three scales intended to measure student test anxiety, communication anxiety, and social anxiety (survey items included as Supplemental Table 4). The test anxiety scale was from the Motivated Strategies for Learning Questionnaire (Pintrich et al., 1991). The scale is composed of five items, measured via a 7-point Likert scale. Student responses to the test anxiety scale were averaged to arrive at a mean test anxiety score for each student. Mean scores range from 1 to 7 , with the higher numbers indicative of higher anxiety.

Both the communication and social anxiety scales were taken from the Personal Report of Communication Apprehension-24 (McCroskey, 1982). These scales are both composed of six items, measured via 5-point Likert scales. Final scores for these instruments were calculated based on the protocol provided by McCroskey (1982): 18 + (scores for positively worded items) - (scores for negatively worded items). Each final score ranges from 6 to 30, and the higher the final score, the higher the anxiety. Partial confirmatory factor analyses on the test, communication, and social anxiety scales all resulted in one-factor solutions. Full factor analysis results, including calculated best-fit indexes and Cronbach's reliability values (Cronbach's $\alpha$ all $\geq 0.859$ ) can be found in Supplemental Tables 5 and 6 .

In addition to measures of student anxiety, self-reported demographic information regarding year in school (freshman, sophomore, junior, senior, super senior), gender identity (male, female, other, or prefer not to respond), racial/ethnic identity (open response), and number of AP courses completed in high school $(0,1,2,3$, or $3+)$ was also collected. The number of AP courses taken was used as a measure of college preparation and potential confidence to succeed, not as a measure of academic ability. Students also self-reported the names of their course instructors.

For the dependent variable of persistence, students were asked on the final survey whether they had changed their intended majors since the beginning of the semester (yes or no). To collect the dependent variable of performance, with student permission, students' final course grades were collected from instructors after grade submission had closed for the 
semester. Thus, the dependent variables of persistence and performance were collected once at the end of the semester, the demographic independent variables were collected once at the beginning of the semester, and the independent variables related to anxiety and difficulty were collected twice over the semester (initial and final surveys).

\section{Data Analysis}

Data from students who indicated they were under the age of 18 or students who did not consent to the use of their data were removed. The Fall initial survey had a total 861 responses across all sections of OEB and CMB (67\% completion rate). The Fall final survey had a total of 677 responses across all sections of OEB and CMB (52\% completion rate). For all data analyses, we included only students for whom we had matched initial and final survey responses and for whom we had permission to acquire their final course grades (final $N=337$ ).

Because the scales varied among the anxiety and perceived difficulty instruments, raw scores were converted to z-scores to facilitate comparisons across instruments. We also created a correlation matrix to examine the relationships among the variables (see Supplemental Table 7). There was only one strong correlation between final general class anxiety and final perception of difficulty at 0.751 ; all other correlations were relatively weak or low. Given the lack of strong correlations among almost all of the variables, we retained all variables in the analyses. However, to eliminate any concerns about correlations between initial and final measures of the same anxiety variables, we decided to test the initial and change in anxiety from the beginning to the end of the semester (delta; final minus initial measure) as the independent anxiety variables.

For data analysis, gender was pared down to male and female, as the other two categories had very few respondents. Ethnicity was coded into Caucasian versus non-Caucasian based on student free responses to this question. Responses such as "white," "Caucasian," and "European American" were coded as Caucasian. All other demographic groups were coded as non-Caucasian. Further parsing of the non-Caucasian category was not possible due to limited diversity in the sample. The survey was disseminated to students across seven sections (each with a unique instructor), but there were no students in the seventh course section who completed both surveys, so that course instructor was excluded from the analysis.

The introductory courses that were the focus of this study included both biology majors, and pre-professional and other majors. Because we were only interested in the persistence of biology majors as a function of these introductory biology courses for the persistence analyses, we reduced this sample of students to include only those who took both surveys and indicated at the beginning of the semester that they were biology majors $(N=122)$. At the end of the Fall semester, there were 80 biology majors who indicated they were remaining, and there were 42 biology majors who indicated they were leaving.

\section{Modeling the Relationships of Anxiety, Difficulty, Demographics, Instructor, and Student Performance}

To assess the impacts of the anxiety, difficulty measures, demographics, and instructor on final student performance (letter grade earned), four models were developed. One model was an ordinal regression with all independent variables included (full model), and the second was an ordinal regression using a backward-selection procedure (best-fit model). To account for nonindependence among students within the same class, two mixed-effects models were also developed (Theobald, 2018). When evaluated with the ordinal package in $\mathrm{R}$ (Christensen, 2018), the latter two models replicated the fixed variables selected in the previous full and best-fit ordinal models, with the addition of instructor as a random effect. For determination of the most parsimonious performance model, measures of Akaike's information criterion (AIC) were calculated and compared between models. All modeling was conducted in the $\mathrm{R}$ language environment (v. 3.3.1; R Core Team, 2018).

For all models, the dependent variable was letter grade earned ("A" = 5, "B" = 4, “C" = 3, "D" = 2, "F" = 1 ; note that plus and minus grade designations were not used for this analysis). The independent variables included initial and delta (final survey measures minus initial survey measures) Z-scores of the following: general class anxiety (GA), perception of difficulty (PD), test anxiety (TA), communication anxiety (CA), and social anxiety (SA). Independent variables of gender, year, ethnicity, and number of AP courses ( $0-1$ AP courses vs. 2 or more AP courses) were also included. Instructor was treated as an independent variable or random effect, depending on the model. In the ordinal regression model, Instructor 6 was chosen as the comparison instructor against which all other instructors were compared; Instructor 6 had a normal grade distribution. Thus, the full initial model was as follows: letter grade earned $\sim$ initial GA + initial PD + initial TA + initial CA + initial SA + delta GA + delta PD + delta TA + delta CA + delta SA + gender + year + ethnicity $+\mathrm{AP}+$ instructor.

\section{Modeling the Relationships of Anxiety, Difficulty, Demographics, Instructor, and Student Persistence}

To assess the impacts of anxiety, difficulty measures, demographics, and instructor on student persistence (a student's intention to remain in or leave the major at the end of the semester), four models were again developed. A logistic regression with all independent variables (full model) was first constructed, followed by a second logistic regression using a backward-selection procedure (best-fit model). Similar to the student performance models, the third and fourth models accounted for instructor as a random effect (Theobald, 2018). These models replicated the variables found in the full and bestfit logistic regressions, respectively, with the addition of instructor as a random effect. Again, AICs for each model were calculated and compared to determine the best-fit model. The dependent variable was whether students indicated they were either leaving or remaining in the biology major. The same independent variables were used as in the ordinal regression model for student performance, again with both initial and delta measures (as z-scores) included. Thus, the full initial model was as follows: leaving or remaining in the major initial GA + initial PD + initial TA + initial CA + initial SA + delta $\mathrm{GA}+$ delta $\mathrm{PD}+$ delta TA + delta CA + delta SA + gender + year + ethnicity $+\mathrm{AP}+$ instructor.

\section{Investigating Differences in Anxiety and Difficulty among Demographic Subsets of Students}

We also investigated the relationships between student demographic variables (gender, year in school, ethnicity, and number 
of AP courses) and general class anxiety, perceived difficulty, test anxiety, social anxiety, and communication anxiety measures. Two multiple linear regression models were created for each anxiety and difficulty measure, one with the initial value and one with the delta value (z-scores were used for each; SPSS v.22; IBM Corporation, 2013). All predictor variables for this model were categorical: freshman versus nonfreshman, Caucasian versus non-Caucasian, male versus female, and 0-1 AP courses versus 2 or more AP courses. Predictors were considered significant at $p<0.05$. All predictors were dummy coded as 0 or 1: 0 for freshmen, 0 for females, 0 for non-Caucasians, and 0 for those with $0-1$ AP courses. Hierarchical forward regression was used, meaning variables were entered into the model based on greatest increment to the $R^{2}$ value. AIC and Bayesian information criterion (BIC) values were used to determine the best-fit model produced. The full initial models all followed the same format: [type of initial anxiety or perceived difficulty $] \sim$ gender + year + ethnicity + AP. The full delta models all followed the same format: [type of delta anxiety or perceived difficulty] $\sim$ gender + year + ethnicity + AP.

\section{RESULTS}

Of the 337 students who completed both surveys and allowed the researchers to access their final grades, 134 students earned an "A," 142 earned a "B," and 61 earned lower than a "B." Of these 337 students, 242 were female, 140 were freshmen, and 280 were Caucasian. There were 134 students who had either taken no or only one AP course in high school; 203 students had taken more than one AP course. For the 122 students who completed both surveys and started the semester as biology majors, 80 students indicated they were continuing in the major, but 42 indicated they were not. In terms of distribution of students across courses, the sample sizes for Instructors 1-6 were as follows, respectively: 78, 36, 81, 37, 32, and 73 .

Before $z$-score conversion, means were calculated for all anxiety and difficulty scales. Of the constructs measured using a 7-point Likert scale, student test anxiety was consistently higher than perceived difficulty and general class anxiety for both the initial and final surveys (Table 1) and was the only measure above the midpoint of the Likert-scale average. For the anxiety measures ranging from 6 to 30, communication anxiety was consistently higher than social anxiety, and always above the midpoint on the measurement scale on both the initial and final surveys (Table 1). There were no significant differences between the overall means on the initial and final surveys for any of the variables measured.

TABLE 1. Means of the student sample $(N=337)$ for each measure of anxiety and perceived difficulty on the initial and final surveys ${ }^{a}$

\begin{tabular}{lcc}
\hline Variable measured & $\begin{array}{c}\text { Mean } \\
\text { (initial survey) }\end{array}$ & $\begin{array}{c}\text { Mean } \\
\text { (final survey) }\end{array}$ \\
\hline General class anxiety & 2.70 & 2.74 \\
Perceived difficulty & 3.71 & 3.81 \\
Test anxiety & 4.15 & 4.10 \\
Communication anxiety & 20.00 & 20.07 \\
Social anxiety & 15.69 & 15.47 \\
\hline
\end{tabular}

a Communication and social anxieties are on a scale ranging from 6 to 30; all others are on a scale ranging from 1 to 7 . In all cases, the higher the mean, the higher the anxiety. There were no significant differences between the means on the initial and final surveys for any of the variables measured.

\section{Modeling the Relationships of Anxiety, Difficulty, Demographics, Instructor, and Student Performance}

Backward selection produced the best-fit ordinal model with an AIC of 708.440 and produced the best-fit mixed-effects model with an AIC of 708.040 (Supplemental Table 8). The ordinal regression model is presented as the best-fitting model given the nearly identical AIC values.

The ordinal regression model estimated which grades students were more or less likely to earn based on the independent variable predictors. The estimates and standard errors for the model are provided in Table 2 . In the model, the dependent variable was letter grade, with "A" $=5$ and "F" $=1$. The estimates suggest which direction student grades will move based on those predictors. For example, a negative estimate (coefficient) pulls the score closer to 1 , which is equal to a letter grade of " $\mathrm{F}$ "; conversely, a positive estimate pulls the score closer to 5, or an "A." The model produced two significant scale predictors: delta perceived difficulty and delta communication anxiety. An increase in perceived difficulty over the semester was associated with lower course performance (estimate of -0.442 , SE $\pm 0.198, p=0.023$ ); interestingly, an increase in communication anxiety was associated with higher performance (estimate $0.38, \mathrm{SE} \pm 0.177, p=0.03$ ). Three demographic variables were significant in the model. Females (estimate -0.734 , SE $\pm 0.267, p=0.006$ ), non-Caucasians (estimate

TABLE 2. Estimates and SEs for the best-fit ordinal regression model predicting final earned grade (performance) $(N=337)^{a}$

\begin{tabular}{lcc}
\hline Independent variable $^{\mathrm{b}}$ & Estimate & SE \\
\hline Initial GA & -0.344 & 0.197 \\
Delta GA & -0.091 & 0.211 \\
Initial PD & -0.353 & 0.203 \\
Delta PD & $-0.442^{*}$ & 0.198 \\
Initial TA & -0.101 & 0.184 \\
Delta TA & -0.308 & 0.184 \\
Initial CA & 0.340 & 0.176 \\
Delta CA & $0.380^{*}$ & 0.177 \\
Initial SA & -0.086 & 0.153 \\
Delta SA & -0.050 & 0.164 \\
Female & $-0.734^{* *}$ & 0.269 \\
Freshman & 0.215 & 0.318 \\
Non-Caucasian & $-0.614^{*}$ & 0.290 \\
0-1 AP courses & $-1.093^{* *}$ & 0.241 \\
Compared with I6: & & \\
I1 & 0.391 & 0.351 \\
I2 & 0.957 & 0.493 \\
I3 & 0.335 & 0.449 \\
I4 & 0.462 & 0.430 \\
I5 & $-0.835^{*}$ & 0.425
\end{tabular}

an the model, "A" = 5 and " $\mathrm{F} "=1$. A negative estimate would indicate a student is more likely to earn a lower grade as the independent variable increases; a positive estimate brings students to a higher grade as the independent variable increases. For example, a 1-point increase in the change in perceived difficulty across the semester would lower a student's grade by $\sim 0.442$ points on a 5-point letter grade scale. Identifying as female would lower one's final grade by $\sim 0.734$ points on a 5 -point letter grade scale. Nagelkerke (pseudo $R^{2}$ ) $=0.262$.

${ }^{\mathrm{b}} \mathrm{CA}$, communication anxiety; GA, general class anxiety; I1-I6, Instructors 1-6; $\mathrm{PD}$, perception of difficulty; SA, social anxiety; TA, test anxiety.

$* p<0.05$.

$* * p<0.01$. 

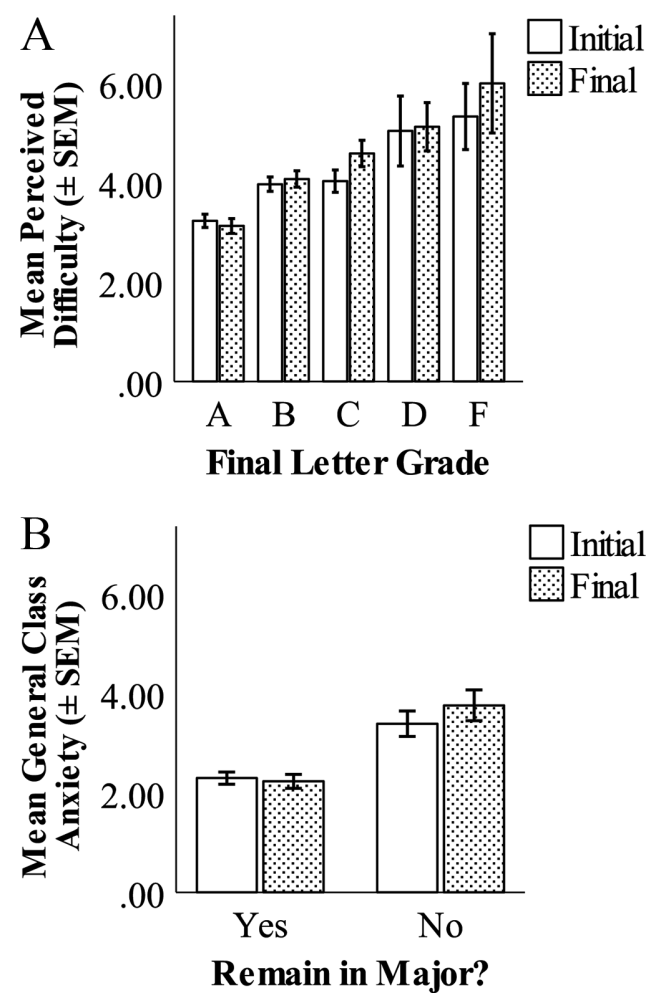

FIGURE 1. (A) Students $(N=337)$ who perceived the class as less difficult, even at the start of the semester, earned higher final letter grades. However, only change in perceived difficulty over the semester (delta) was predictive of course performance in our model. (B) Biology majors ( $N=122)$ who reported leaving the major had higher initial and final general class anxiety. However, only initial general class anxiety levels were predictive of intention to persist in the major. The Likert scale is $1-7$, with 1 being no general class anxiety/perceived difficulty and 7 being high general class anxiety/perceived difficulty. Data are mean general class anxiety or perceived difficulty \pm SEM.

-0.614 , SE $\pm 0.293, p=0.03$ ), and those with 0-1 AP courses (estimate -1.093 , SE $\pm 0.241, p<0.001$ ) were negatively associated with performance, meaning lower grades. Students who had Instructor 5 showed negative associations with performance, meaning earning lower letter grades as compared with students who had Instructor 6; however, this was the only significant result found among all instructors. To visualize average perceived difficulty measures by student performance categories, a bar chart of average initial and final (not delta) perceived difficulty scores by students' final earned grade was created (Figure 1A).

\section{Modeling the Relationships of Anxiety, Difficulty,} Demographics, Instructor, and Student Persistence

We initially produced a full logistic regression model in SPSS (AIC 138.490); treating instructor as a random effect using mixed-effects models in $\mathrm{R}$ produced a model with an AIC of 134.046. Using backward selection, we resolved on the full logistic regression model with an AIC 138.490 as the best-fit model (Supplemental Table 8). Lower AIC values are considered an indication of better fit; however, there exists no
TABLE 3. Odds ratio and $95 \% \mathrm{Cls}$ based on best-fit binary logistic regression model for students indicating they were leaving the major (persistence) $(N=122)^{a}$

\begin{tabular}{|c|c|c|c|}
\hline Independent variable $^{b}$ & $\begin{array}{c}\text { Odds ratio for } \\
\text { student leaving }\end{array}$ & $\begin{array}{l}\text { Lower } \\
95 \% \text { CI }\end{array}$ & $\begin{array}{c}\text { Upper } \\
95 \% \text { CI }\end{array}$ \\
\hline Initial GA & $4.446 * *$ & 1.794 & 11.019 \\
\hline Delta GA & 1.806 & 0.683 & 4.777 \\
\hline Initial PD & 0.978 & 0.394 & 2.432 \\
\hline Delta PD & 1.050 & 0.433 & 2.543 \\
\hline Initial TA & 0.958 & 0.510 & 2.612 \\
\hline Delta TA & 1.198 & 0.531 & 2.701 \\
\hline Initial CA & 1.119 & 0.549 & 2.283 \\
\hline Delta CA & 1.783 & 0.746 & 4.258 \\
\hline Initial SA & 0.566 & 0.238 & 1.348 \\
\hline Delta SA & 1.226 & 0.517 & 2.907 \\
\hline Female & $5.779 * *$ & 1.616 & 20.667 \\
\hline Freshman & 1.241 & 0.260 & 5.921 \\
\hline Non-Caucasian & 0.511 & 0.108 & 2.420 \\
\hline 0-1 AP courses & 2.349 & 0.748 & 7.370 \\
\hline \multicolumn{4}{|l|}{ Compared with I6: } \\
\hline I1 & 1.629 & 0.199 & 13.300 \\
\hline $\mathrm{I} 2$ & 0.763 & 0.76 & 7.661 \\
\hline I3 & 1.465 & 0.172 & 12.448 \\
\hline I4 & 0.565 & 0.066 & 4.852 \\
\hline I5 & 0.158 & 0.007 & 3.723 \\
\hline
\end{tabular}

an odds ratio of 1 indicates a student is equally likely to report remaining in or leaving the major. A higher odds ratio indicates one group is more likely than the other to report leaving the major; a lower odds ratio indicates that group is less likely to report leaving the major compared with the other group. Nagelkerke (pseudo $R^{2}$ ) $=0.480$.

${ }^{\mathrm{b}} \mathrm{CA}$, communication anxiety; GA, general class anxiety; I1-I6, Instructors 1-6; $\mathrm{PD}$, perception of difficulty; SA, social anxiety; TA, test anxiety.

$* * p<0.01$.

statistical test for determining whether two AIC values are truly different. It has been argued that, when two AIC values show a difference of less than 5 units, this constitutes less than certain evidence of greater model fit (Burnham and Anderson, 1998; Burnham et al., 2011). Occasionally, interpretability of results can be a factor in model selections, and models with slightly higher AICs may be preferable due to ease of interpretation. For ease of interpretability, the logistic regression model without random effect is the model presented here.

The logistic regression model produced an odds ratio indicating the likelihood that a student will either remain in the major or not. The odds ratio is the exponent of the regression coefficient calculated in the model and ranges from zero to infinity. An odds ratio greater than 1 indicates that a student is more likely to remain in a certain category as opposed to a reference category against which it is compared. The logistic regression results are reported in Table 3. A 1-point increase in the initial general class anxiety score of a student indicates that, for every student who reported staying in the major, 4.446 times as many students reported leaving the major $(p<0.001$, $95 \%$ CI $[1.794,11.019])$. The odds of females reporting leaving the major were 5.779 times greater than the odds of males leaving the major ( $p=0.007,95 \%$ CI $[1.616,20.667])$. To visualize general class anxiety scores (initial and final values from the surveys) by intention to persist, a bar chart of general class 
TABLE 4. Regression predictor values, SEs, and $p$ values for initial and delta (final minus initial) values of general class anxiety for demographic subsets of the class $(N=337)^{\text {a }}$

\begin{tabular}{lccccccc}
\hline Predictor (initial) & Value & SE & $p$ value & Predictor (delta) & Value & SE & $p$ value \\
\hline Intercept & 0.686 & 0.165 & $<0.01^{* *}$ & Intercept & -0.009 & 0.132 \\
Freshman & -0.384 & 0.108 & $<0.01^{* *}$ & Freshman & -0.188 & 0.086 \\
Female & -0.250 & 0.118 & $0.035^{*}$ & & & $0.030^{*}$ \\
$0-1$ AP courses & -0.308 & 0.109 & $<0.01^{* *}$ & & & \\
\hline
\end{tabular}

${ }^{a}$ Negative coefficient values indicate a negative relationship between general class anxiety and the corresponding demographic variable. For initial: AIC $=281.979$, $\mathrm{BIC}=297.294$; for final: $\mathrm{AIC}=323.027$, $\mathrm{BIC}=334.514$.

${ }^{*} p<0.05$.

$* * p<0.01$.

TABLE 5. Regression predictor values, SEs, and $p$ values for the initial values of perceived difficulty for demographic subsets of the class (the model for the delta values was not significant) $(N=337)^{\text {a }}$

\begin{tabular}{lccl}
\hline Predictor (initial) & Value & SE & $p$ value \\
\hline Intercept & 0.624 & 0.165 & $<0.01^{* *}$ \\
Freshman & -0.331 & 0.108 & $<0.01^{* *}$ \\
Female & -0.311 & 0.118 & $<0.01^{* *}$ \\
0-1 AP courses & -0.320 & 0.109 & $<0.01^{* *}$
\end{tabular}

${ }^{a}$ Negative coefficient values indicate a negative relationship between perceived difficulty and the corresponding demographic variable. For initial: $\mathrm{AIC}=344.683$, BIC $=359.998$.

$* * p<0.01$.

anxiety scores by students' intention to persist in the major was created (Figure 1B).

\section{Investigating Differences in Anxiety and Difficulty among Demographic Subsets of Students}

For the multiple linear regression analyses for general class anxiety, the initial best-fit model (based on the initial general class anxiety measures) was significant $(F=6.355, p<0.001)$, as was the delta best-fit model $(F=2.409, p=0.049)$. These significant models indicated that they were better predictors than a null model with no predictors. At the beginning of the semester, freshmen, females, and those with fewer than 2 AP courses were more likely to have higher perceptions of general class anxiety (Table 4). When examining the change in general anxiety, this trend continued for freshmen.

For the multiple linear regression analyses for perceived difficulty, the initial best-fit model was significant $(F=6.010$, $p<0.001)$, but the delta best-fit model was not $(F=1.199$, $p=0.311$ ). At the beginning of the semester, freshmen, females, and those with fewer than two AP courses were more likely to perceive higher levels of difficulty regarding the course (Table 5). Change in perceptions of difficulty (delta) showed no measurable difference between demographic subsets.

The multiple linear regression analyses for communication anxiety were significant for both the initial $(F=6.619, p<0.01)$ and delta $(F=2.512, p=0.042)$ models. At the start of the semester, females and those with 0-1 AP courses were more likely to perceive higher levels of communication anxiety in the course. When change in communication anxiety was measured, freshman communication anxiety remained relatively stable from the initial to the final survey, while communication anxiety in nonfreshmen decreased slightly (Table 6).

The multiple linear regression models for test and social anxiety can be found in Supplemental Tables 9 and 10. There were gender differences and year differences for test anxiety; social anxiety differences existed between genders, years, and ethnicity, but only at the start of the semester. These detailed results are included in the Supplemental Material, because social and test anxiety were not found to impact persistence or performance in the course.

\section{DISCUSSION}

This study investigated the relationships among different types of anxiety and perceived course difficulty at different times of the semester, student demographics, instructor, and student course performance and persistence in the major. We found that an increase in student perception of difficulty by the end of the semester was related to decreased course performance, and an increase in communication anxiety was associated with increased course performance. General class anxiety at the start of the semester was inversely related to persistence in the major. Test and social anxiety were not related to performance or persistence in this study. Our study also revealed that females, freshmen, and students with fewer AP courses typically had higher general class anxiety and perceptions of difficulty, but it was only females who were also more likely to have lower

TABLE 6. Regression predictor values, SEs, and $p$ values for the initial and delta (final minus initial) values of communication anxiety for demographic subsets of the class $(N=337)^{\text {a }}$

\begin{tabular}{lccccccc}
\hline Predictor (initial) & Value & SE & $p$ value & Predictor (delta) & Value & SE & $p$ value \\
\hline Intercept & 0.168 & 0.164 & 0.307 & Intercept & 0.313 & 0.137 \\
Female & -0.511 & 0.117 & $<0.01^{* *}$ & & & \\
0-1 AP courses & -0.250 & 0.108 & $<0.05^{*}$ & & &
\end{tabular}

$\begin{array}{llll}\text { Freshman } & -0.218 & 0.089 & 0.015^{*}\end{array}$

${ }^{a}$ Negative coefficient values indicate a negative relationship between communication anxiety and the corresponding demographic variable. For initial: AIC $=1178.398$, $\mathrm{BIC}=1189.884$; for final: $\mathrm{AIC}=1126.082$, $\mathrm{BIC}=1137.560$

$* p<0.05$.

$* * p<0.01$. 
grades and leave the major (those with fewer AP courses had lower performance only). Conversely, non-Caucasian students were more likely to receive lower grades, but did not have different levels of general class anxiety or perceptions of difficulty compared with Caucasian students. Freshmen had higher general class anxiety and perceptions of difficulty compared with nonfreshmen, but had no differentials in performance or persistence. Taken together, these results suggest that some student emotions do impact performance and persistence but certain groups of students in introductory biology are more negatively impacted than others.

\section{Perceived Difficulty Related to Student Performance}

It is perhaps not surprising that changes in perceived course difficulty by the end of the semester were related to performance in the class. While perceived difficulty is not synonymous with anxiety, we hypothesize it is a direct antecedent to emotions such as anxiety. The difficulty scale asked students to rate their perceptions of whether the course was complex, complicated, and difficult, perceptions that would be used to appraise the demands of the course and judge the resources needed to succeed. Students overall consistently rated perceived difficulty higher than the general class anxiety items, suggesting that most students were able to meet the course demands and manage their anxiety. However, at week 14, the students who were going to earn lower grades in the class perceived the class as more difficult. This aligns with the expectancy-value theory of achievement motivations (Wigfield and Eccles, 2000), which posits that students' performances are partially explained by how well students feel they can perform on a task. It would be interesting to capture perceived difficulty more frequently through the semester to determine at what point in the semester perceived difficulty becomes predictive of performance.

If students anticipate performing poorly on a task, their goal may be to avoid the need to achieve altogether, a phenomenon known as performance avoidance (Elliot and Harackiewicz, 1996). Performance avoidance has been linked to reduced motivation and achievement (Elliot and Church, 1997; Richardson et al., 2012). It may also be worth investigating what classroom emotions were associated with higher perceived difficulty ratings, with the presumption that, instead of anxiety, students may feel a nonactivating emotion such as hopelessness (Pekrun and Stephens, 2010). Given that perceptions of difficulty were not related to persistence, it may be that students attribute difficulty to a particular instructor or course topic and are less likely to judge their future success in the major based on one course. For example, students found Instructor 5 more difficult, as seen in the ordinal regression model. Students in that instructor's section were more likely to earn lower grades compared with the reference variable, which in this case was Instructor 6. All instructors within the same course (OEB or CMB) taught the same content, but not all students perceived the courses as equally difficult. Because there were no shared exams in these courses, these results may be explained by differences in exam difficulty among instructors (e.g., Instructor 5 vs. other instructors), which may have differentially impacted students.

\section{General Class Anxiety Related to Student Persistence}

General class anxiety was not predictive of student performance in our model, but it was predictive of student persistence.
Higher levels of general class anxiety were positively associated with - and predictive of - a student's intention to leave the major. In our model, this was found only at the beginning of the semester, indicating that prospective anxiety early in one course can impact students' persistence in the major. This suggests that, just as students may perceive difficulty to be a function of a particular course, general class anxiety may be perceived as a future judgment on success in a degree program. There is a dearth of literature regarding the reasons why some students may come into the classroom with higher anxiety. There have been anecdotal reports of negative experiences with previous science classes and/or teachers, negative stereotypes of scientists, lack of role models, poor academic advising, and perpetuation of the myth that only a select few are capable of being scientists (Mallow and Greenburg, 1982; Mallow, 2006). Some of these reasons correlate with recent work in our lab that indicates students' presemester anxiety is driven by previous science course experiences, perceptions of difficulty of the subject, the length of time since their last biology course, not knowing what to expect, and concern about instruction and size of class (E.E.S., B.J.E., and J.R.B., unpublished data). However, these reasons remain untested and bound by our institutional context and should be considered tentative explanations.

The finding that anxiety impacts persistence is aligned with other recent studies (Witt et al., 2014; Barthelemey et al., 2015; England et al., 2017; Respondek et al., 2017). Respondek et al. (2017) found that anxiety was negatively related to persistence, but not academic performance, supporting the idea that anxiety has more long-term versus short-term impacts on student perceptions of success. One potential explanation is that students may be able to deploy effective coping strategies to deal with their anxiety related to performance but are unable to extend this to persistence (Boekaerts and Pekrun, 2015). Previous studies have indicated that the use of coping is correlated with persistence, but not necessarily with the amount of anxiety (Shields, 2001). How students employ coping in regard to performance versus persistence is an area that needs further exploration.

\section{Differential Performance and Persistence of Students Subsets}

The findings that several demographic groups had differential performance and persistence support an extensive literature base on differential outcomes for subsets of students in science. Studies identifying gender differences in performance and persistence are common in the biology education literature (Eddy et al., 2014; Eddy and Brownell, 2016) and are thought to contribute to the lower than expected numbers of females in science (National Science Foundation [NSF], 2011). Academic performance differences between Caucasians and non-Caucasians are consistent with other studies (Greene et al., 2008; Eddy and Hogan, 2014), and higher numbers of completed AP courses were linked with higher student grade point averages (GPAs) and graduation rates in a 10-year-long study at one institution (Ackerman et al., 2013).

An opportunity in this study was to examine potential links between general class anxiety and/or perception of difficulty and student performance and/or persistence for particular demographic groups. When the results of all the models were 
looked at collectively, the following trends emerged. Females had lower performance and persistence than males and reported higher perceived class difficulty and general class anxiety. However, higher levels of general class anxiety and perceived class difficulty only decreased performance in students with fewer AP courses and did not decrease performance or persistence in freshmen, and non-Caucasians had decreased performance without differentials in perceived difficulty or general class anxiety. Thus, differentials in general class anxiety and perceived difficulty are not always aligned with decreased student success in these groups, or vice versa. This could be explained by different emotional regulation within each subset. Females and males, for example, may have different mechanisms of coping, with female students consistently reporting more anxiety than male students (Misra and McKean, 2000; Bayram and Bilgel, 2008; Bryant et al., 2013) and higher use of emotion-focused coping (Brougham et al., 2009). In this sense, it is possible that females and students with fewer AP courses may feel that they do not have the cognitive and affective resources to manage the sources of anxiety, non-Caucasians may use emotion-focused coping (such as avoidance) to decrease their anxiety but without helping their performance, and freshmen may use their confidence generated from their recent high school successes to ameliorate some of the negative impacts of anxiety. Analyzing coping strategies within each of these subsets in introductory biology would be a worthy follow-up to this study.

Many of the impacted subsets of students in this study come from traditionally marginalized groups in science who sometimes feel they do not belong in the science classroom (Grunspan et al., 2016). This has negative impacts on self-efficacy, which is inversely related to anxiety (Bandura, 1989). Although there are many potential causes of these differentials, recent work has highlighted classroom climate issues that could impact emotional responses. For example, factors such as professor-student interactions, student-student interactions, and classroom pedagogical practices may influence how these groups perceive the course and experience anxiety (Barthelemey et al., 2015). Classroom differentials, such as professors being more likely to call on males in class (Eddy et al., 2014) or females not being conferred the same respect for intellectual abilities that male students are in introductory biology (Grunspan et al., 2016), may lead to disenfranchisement and decreases in self-efficacy. This fits well with the control-value theory of achievement emotion (Pekrun, 2006) because of the impact of classroom context, including instructor, on student emotion and the iterative nature of student experiences that may solidify particular emotions in particular student subsets based on their common classroom experiences.

\section{Active Learning and Anxiety}

This study originated as a follow-up to work showing student anxiety toward particular active-learning practices in introductory classes (England et al., 2017). Thus, we investigated types of anxiety that may be related to active-learning practices and their potential impacts on student performance and persistence. Neither communication nor social anxiety measures were predictive of either student performance or persistence, with one notable exception: An increase in communication anxiety over the semester was associated with higher grades. This counters work by McCroskey et al. (1989), who found that higher communication apprehension lowered student GPAs, although this study was a longitudinal design and not focused on active-learning classrooms. The items designed to measure communication anxiety were focused on answering questions in front of peers. Although most anxiety impacts are negative, they can vary by individual (Pekrun et al., 2007) and have a modulating effect on performance (Yerkes and Dodson, 1908; Keeley et al., 2008). It is possible that a high level of communication anxiety "kept students on their toes" and made them more engaged in anticipation of possibly being asked a question. It is possible that certain instructors invoked a level of communication anxiety in their students that fostered higher engagement (Mazer et al., 2014).

The lack of association between higher social and communication anxieties and decreased performance or persistence supports the body of evidence on the positive impacts of active-learning practices on student performance (Freeman et al., 2014) and once again invokes an explanation suggested by the Yerkes-Dodson law (Yerkes and Dodson, 1908) that, even if active learning causes anxiety, its impact is more likely to activate performance rather than inhibit it. Cooper et al. (2018) found that active-learning practices can both increase and decrease student anxiety in the classroom. It also may not be the increase or decrease in anxiety that matters for student success, but the presence of an optimal amount of anxiety overall. Both communication anxiety and social anxiety are known to exist in introductory classrooms (Broeckelman-Post et al., 2016; England et al., 2017; Cooper et al., 2018) and were found to vary by demographic group in this study, yet they were not factors in differential student success. Although not related to active learning per se, test anxiety was also found to be relatively high in students in this study, and differed for females and students with fewer AP courses, yet was not related to performance or persistence in this sample. This is counter to many findings that test anxiety is related to performance in college classes (Culler and Holahan, 1980; Chapell et al., 2005); however, the impacts of test anxiety likely vary based on the specific courses and assessment practices in those courses. Overall, it appears that the anxiety that impacts student success in these introductory biology classes is broader than individual active-learning practices or test anxiety. Further research is needed to investigate what classroom aspects are driving measures of general class anxiety and perceived difficulty in these classes.

\section{Implications, Limitations, and Conclusion}

The control-value theory of achievement emotions (Pekrun, 2006; Pekrun et al., 2007) indicates that emotions that students experience in the classroom are the manifestations of their appraisal of the value and control they feel in the class. However, the control-value theory also suggests that these appraisals and reactions can be regulated (Pekrun, 2006; Boekaerts and Pekrun, 2015). Students, for example, can learn to adjust their appraisals of value and control or cope with their emotional responses (Pekrun, 2006; Carter, 2010). Thus, there are strategies that could be tested to help females, for example, appraise their perception of control over their achievement outcomes or perhaps cope with anxiety they may be feeling in the classroom. Active coping in particular has been shown to 
help with student persistence and better college adjustment, although not with GPA (Leong et al., 1997; Shields, 2001). These findings align with Dweck's (1986) and Bandura's (1989) work on motivation and self-efficacy, suggesting that resilience in the face of challenge and high self-efficacy maintains student persistence and effort.

These coping strategies could be tested in a quasi-experimental manner in introductory biology classrooms to see whether they can equalize some of the performance and persistence impacts that some groups experience in these classes. These coping strategies should also be generally useful in other STEM courses, perhaps helping student success in courses outside biology (Conley et al., 2013). Alternatively, interventions that modify the curriculum or instructor practices may also be pivotal in helping subsets of students equalize their performances in the class (Eddy and Hogan 2014; Mazer et al. 2014). While documenting anxiety differentials and their potential impacts on performance and persistence is an important step, interventions to address these imbalances need to be tested.

There are several limitations to the findings we report in this study. The results were from a sample of students from one set of introductory courses at one university; thus, these results may not be generalizable to other institutions. The sample was also voluntary and heavily female and Caucasian. Although we intended to use the number of AP classes as a measure of college preparation and confidence, it is also likely conflated with disparity in academic access for many students. We were unable to collect a variable that would capture prior academic performance or ability to serve as a covariate in this study. Because students opted to respond to the survey or not, the sample may be biased toward those students who are more likely to share their anxiety experiences. We also do not have information on performance or persistence of the students who did not take the survey and thus cannot judge the potential bias of the sample. Furthermore, we do not know the specific course factors that were causing students to feel anxiety, or even if they were similar from course to course. Instructor was not a major factor in our models, but should be further explored in regard to impacts on particular subsets of students. Although mostly similar in size, one class was smaller than the others, and the impacts of different class sizes on anxiety and student outcomes could be a factor as well. There could also be many other factors outside the introductory biology courses of interest that would affect student performance and persistence, such as course load, student employment, or personal issues, none of which were explored in this study. Finally, the links between measures of general class anxiety or perceived difficulty and performance and persistence for the different demographic groups were only correlations. There are no causative links that can be drawn from this work.

This study investigated the relationships among different types of anxieties, demographic subsets of students, instructor, and student performance and persistence in introductory biology at one university. We found that general class anxiety, perceived difficulty, and communication anxiety had complicated links with performance and persistence, with higher levels of each at certain times of the semester impacting some measures of student success, particularly for females. It is likely that students appraise multiple aspects of the course to arrive at perceptions of anxiety and difficulty, yet these aspects are currently unknown. For certain subsets of students in the classes, their emotional experiences, appraisals, and coping are different from the rest of the class, leaving them vulnerable in terms of STEM retention and success. Further research on anxiety in the classroom is imperative to determine the actions instructors can take to address the STEM attrition crisis.

\section{ACKNOWLEDGMENTS}

We thank the instructors who helped us conduct this research, the students who participated in the surveys, and peer reviewers who improved this work. Liam Mueller and Elli Theobald provided invaluable assistance with the statistical analyses. This research was funded in part by an NSF TUES grant (DUE 1245215; E.E.S., principal investigator).

\section{REFERENCES}

Ackerman, P. L., Kanfer, R., \& Calderwood, C. (2013). High school advanced placement and student performance in college: STEM majors, non-STEM majors, and gender differences. Teachers College Record, 115(10), 1-43.

Akgun, S., \& Ciarrochi, J. (2010). Learned resourcefulness moderates the relationship between academic stress and academic performance. Educational Psychology, 23(3), 287-294. https://doi.org/10.1080/ 0144341032000060129

American Association for the Advancement of Science (AAAS). (2011). Vision and change in undergraduate biology education: A call to action. Washington, DC. Retrieved June 17, 2016, from http://visionandchange.org/ files/2013/11/aaas-VISchange-web1113.pdf

AAAS. (2015). Vision and change in undergraduate biology education Chronicling change, inspiring the future. Washington, DC. Retrieved June 17, 2016, from http://visionandchange.org/chronicling-change/

Armbruster, P., Patel, M., Johnson, E., \& Weiss, M. (2009). Active learning and student-centered pedagogy improve student attitudes and performance in introductory biology. CBE-Life Sciences Education, 8(4), 203-213. https://doi.org/10.1187/cbe.09-03-0025

Bandura, A. (1989). Human agency in social cognitive theory. American Psychologist, 44(9), 1175-1184. https://doi.org/10.1037/0003-066X.44 9.1175

Barthelemey, R. S., Hedberg, G., Greenberg, A., \& McKay, T. (2015). The climate experiences of students in introductory biology. Journal of Microbiology \& Biology Education, 16(2), 138-147. https://doi.org/10 .1128/jmbe.v16i2.921

Bayram, N., \& Bilgel, N. (2008). The prevalence and socio-demographic correlations of depression, anxiety, and stress among a group of university students. Social Psychiatry and Psychiatric Epidemiology, 43(8), 667672. https://doi.org/10.1007/s00127-008-0345-x

Bitsko, R. H., Holbrook, J. R., Ghandour, R. M., Blumberg, S. J., Visser, S. N., Perou, R., \& Walkup, J. T. (2018). Epidemiology and impact of health care provider-diagnosed anxiety and depression among US children. Journal of Developmental \& Behavioral Pediatrics, 39(5), 395-403. https://doi .org/10.1097/DBP.0000000000000571

Bledsoe, T. S., \& Baskin, J. J. (2014). Recognizing student fear: The elephant in the classroom. College Teaching, 62(1), 32-41. https://doi.org/10 .1080/87567555.2013.831022

Boekaerts, M., \& Pekrun, R. (2015). Emotions and emotion regulation in academic settings. In Como, L., \& Anderman, E. M. (Eds.), Handbook of educational psychology (pp. 76-90). New York: Routledge.

Bowers, J. W. (1986). Classroom communication apprehension: A survey Communication Education, 35(4), 372-378. https://doi.org/10.1080/ 03634528609388361

Broeckelman-Post, M., Johnson, A., \& Schwebach, J. R. (2016). Calling on students using notecards: Engagement and countering communication anxiety in large lecture. Journal of College Science Teaching, 45(5), 2732. https://doi.org/10.2505/4/jcst16_045_05_27

Brougham, R. R., Zail, C. M., Mendoza, C. M., \& Miller, J. R. (2009). Stress, sex differences, and coping strategies among college students. Current Psychology, 28(2), 85-97. https://doi.org/10.1007/s12144-009-9047-0 
Bryant, F. B., Kastrup, H., Udo, M., Hislop, N., Shefner, R., \& Mallow, J. (2013) Science anxiety, science attitudes and constructivism: A binational study. Journal of Science Education and Technology, 22(4), 432-448. https:// doi.org/10.1007/s10956-012-9404-x

Burnham, K. P., \& Anderson, D. R. (1998). Model selection and inference: A practical information-theoretical approach. New York: SpringerVerlag.

Burnham, K. P., Anderson, D. R., \& Huyvaert, K. P. (2011). AIC model selection and multimodel inference in behavioral ecology: Some background, observations, and comparisons. Behavioral Ecology and Sociobiology, 65(1), 23-35. https://doi.org/10.1007/s00265-010-1029-6

Carter, A. (2010). Evaluating the best of coping program: Enhancing coping skills in adolescents (Doctoral dissertation). Ontario, Canada: University of Windsor. Retrieved December 15, 2018, from http://scholar.uwindsor ca/etd/479

Castillo, L. G., \& Schwartz, S. J. (2013). Introduction to the special issue on college student mental health. Journal of Clinical Psychology, 69(4), 291-297. https://doi.org/10.1002/jclp.21972

Chapell, M. S., Blanding, Z. B., Silverstein, M. E., Takahashi, M., Newman, B., Gubi, A., \& McCann, N. (2005). Test anxiety and academic performance in undergraduate and graduate students. Journal of Educational Psychology, 97(2), 268-274. https://doi.org/10.1037/0022-0663.97.2.268

Christensen, R. H. B. (2018). Package "ordinal." Retrieved September 1, 2018, from https://cran.r-project.org/web/packages/ordinal/ordinal.pdf

Conley, C. S., Travers, L. V., \& Bryant, F. B. (2013). Promoting psychosocial adjustment and stress management in first-year college students: The benefits of engagement in a psychosocial wellness seminar. Journal of American College Health, 61(2), 75-86. https://doi.org/10.1080/ 07448481.2012 .754757

Cooper, K. M., \& Brownell, S. E. (2016). Coming out in class: Challenges and benefits of active learning in a biology classroom for LGBTQIA students. CBE-Life Sciences Education, 15(1), ar37. https://doi.org/10.1187/ cbe.16-01-0074.

Cooper, K. M., Downing, V. R., \& Brownell, S. E. (2018). The influence of active learning practices on student anxiety in large-enrollment college science classrooms. International Journal of STEM Education, 5, 23. https://doi.org/10.1186/s40594-018-0123-6

Culler, R. E., \& Holahan, C. J. (1980). Test anxiety and academic performance: The effects of study-related behaviors. Journal of Educational Psychology, 72(1), 16-20. https://doi.org/10.1037/0022-0663.72.1.16

Dweck, C. S. (1986). Motivational processes affecting learning. American Psychologist, 41(10), 1040-1048. https://doi.org/10.1037/0003-066X.41.10.1040

Eddy, S. L., \& Brownell, S. E. (2016). Beneath the numbers: A review of gender disparities in undergraduate education across science, technology, engineering, and math disciplines. Physical Review Physics Education Research, 12(2), 020106.

Eddy, S. L., Brownell, E. S., Thummaphan, P., Lan, M., \& Wenderoth, M. P. (2015a). Caution, student experience may vary: Social identities impact a student's experience in peer discussions. CBE-Life Sciences Education, 14(4), ar45. https://doi.org/10.1187/cbe.15-05-0108

Eddy, S. L., Brownell, S. E., \& Wenderoth, M. P. (2014). Gender gaps in achievement and participation in multiple introductory biology classrooms. CBE-Life Sciences Education, 13(3), 478-492. https://doi.org/10.1187/ cbe.13-10-0204

Eddy, S. L., Converse, M., \& Wenderoth, M. (2015b). PORTAAL: A classroom observation tool assessing evidence-based teaching practices for active learning in large science, technology, engineering, and mathematics classes. CBE-Life Sciences Education, 14(2), ar23. https://doi.org/ 10.1187/cbe.14-06-0095

Eddy, S. L., \& Hogan, K. (2014). Getting under the hood: How and for whom does increasing course structure work? CBE-Life Sciences Education, 13(3), 453-468. https://doi.org/10.1187/cbe.14-03-0050

Elliot, A. J., \& Church, M. A. (1997). A hierarchical model of approach and avoidance achievement motivation. Journal of Personality and Social Psychology, 72, 218-232. https://doi.org/10.1037/0022-3514.72.1.218

Elliot, A. J., \& Harackiewicz, J. M. (1996). Approach and avoidance achievement goals and intrinsic motivation: A mediational analysis. Journal of Personality and Social Psychology, 70, 461-475. https://doi.org/ 10.1037/0022-3514.70.3.461
Endler, N. S., \& Parker, J. D. A. (1990). Stress and anxiety: Conceptual and assessment issues. Stress Medicine, 6, 243-248. https://doi.org/10.1002/ smi.2460060310

England, B. J., Brigati, J. R., \& Schussler, E. E. (2017). Student anxiety in introductory biology classrooms: Perceptions about active learning and persistence in the major. PLOS ONE, 12(8), e0182506. https://doi .org/10.1371/journal.pone.0182506

Freeman, S., Eddy, S. L., McDonough, M., Smith, M. K., Wenderoth, M. P., Okoroafor, N., \& Jordt, H. (2014). Active learning increases student performance in science, engineering, and mathematics. Proceedings of the National Academy of Science USA, 111(23), 8410-8415. https://doi .org/10.1073/pnas.1319030111

Freeman, S., Haak, D., \& Wenderoth, M. P. (2011). Increased course structure improves performance in introductory biology. CBE-Life Sciences Education, 10(2), 175-186. https://doi.org/10.1187/cbe.10 $-08-0105$

Freeman, S., O'Connor, E., Parks, J. W., Cunningham, M., Hurley, D., Haak, D., ... \& Wenderoth, M. P. (2007). Prescribed active learning increases performance in introductory biology. CBE-Life Sciences Education, 6(2), 132 139. https://doi.org/10.1187/cbe.06-09-0194

Gerwing, T. G., Rash, J. A., Gerwing, A. M., Bramble, B., \& Landine, J. (2015). Perceptions and incidence of test anxiety. Canadian Journal for the Scholarship of Teaching and Learning, 6(3), ar3. https://doi.org/10.5206/ cjsotl-rcacea.2015.3.3

Graham, M. J., Frederick, J., Byars-Winston, A., Hunter, A., \& Handelsman, J. (2013). Increasing persistence of college students in STEM. Science, 341(6153), 1455-1456. https://doi.org/10.1126/science.1240487

Greene, T. G., Marti, C. N., \& McClenney, K. (2008). The effort-outcome gap: Differences for African American and Hispanic community college students in student engagement and academic achievement. Journal of Higher Education, 79(5), 513-539. https://doi.org/10.1080/00221546 .2008.11772115

Grossberg, S. (2009). Cortical and subcortical predictive dynamics and learning during perception, cognition, emotion, and action. Philosophical Transactions: Biological Sciences, 364, 1223-1234. https://doi .org/10.1098/rstb.2008.0307

Grunspan, D. Z., Eddy, S. L., Brownell, S. E., Wiggins, B. L., Crowe, A. J., \& Goodreau, S. M. (2016). Males under-estimate academic performance of their female peers in undergraduate biology classrooms. PLOS ONE, 11(2), e0148405. https://doi.org/10.1371/journal.pone.0148405

Haak, D., HilleRisLambers, J., Pitre, E., \& Freeman, S. (2011). Increased structure and active learning reduce the achievement gap in introductory biology. Science, 332(6034), 1213-1216. https://doi.org/10.1126/ science. 1204820

IBM Corporation. (2013). IBM SPSS statistics for Windows (Version 22.0). Armonk, NY.

Jefferson, J. W. (2001). Social anxiety disorder: More than just a little shyness. Primary Care Companion to the Journal of Clinical Psychiatry, 3(1), 4-9.

Karim, N. H. A., \& Shah, M. I. A. (2012). Silence is not golden: Investigating participation anxiety among university students. World Applied Sciences Journal, 20(2), 228-235.

Keeley, J., Zayac, R., \& Correia, C. (2008). Curvilinear relationships between statistics anxiety and performance among undergraduate students: Evidence for optimal anxiety. Statistics Education Research Journal, 7(1), 4-15.

Khanna, M. (2015). Ungraded pop quizzes: Test-enhanced learning without all the anxiety. Teaching of Psychology, 42(2), 174-178. https://doi .org/0.1177/0098628315573144

Kim, C., \& Pekrun, R. (2014). Emotions and motivation in learning and performance. In Spector, J. M. (Ed.), Handbook of research on educational communications and technology (pp. 65-75). New York: Springer Science+Business Media.

Leong, F. T. L., Bonz, M. H., \& Zachar, P. (1997). Coping styles as predictors of college adjustment among freshman. Counselling Psychology Quarterly. 10(2), 211-220. https://doi.org/10.1080/09515079708254173

Mallow, J. V. (2006). Science anxiety: Research and action. In Mintzes, J. J., \& Leonard, W. H. (Eds.), Handbook of college science teaching (pp. 3-14). Arlington, VA: NSTA Press. 
Mallow, J. V., \& Greenburg, S. L. (1982). Science anxiety: Causes and remedies. Journal of College Science Teaching, 11(6), 356-358. Retrieved December 15, 2018, from www.jstor.org/stable/42965923

Mazer, J. P. (2013). Student emotional and cognitive interest as mediators of teacher communication behaviors and student engagement: An examination of direct and interaction effects. Communication Education, 62(3), 253-277. https://doi.org/10.1080/03634523.2013.777752

Mazer, J. P. (2017). Students' discrete emotional responses in the classroom: Unraveling relationships with interest and engagement. Communication Research Reports, 34(4), 359-367. https://doi.org/10.1080/08824096 .2017.1365233

Mazer, J. P., McKenna-Buchanan, T. P., Quinlan, M. M., \& Titsworth, S. (2014). The dark side of emotion in the classroom: Emotional processes as mediators of teacher communication behaviors and student negative emotions. Communication Education, 63(3), 149-168. https://doi.org/ 10.1080/03634523.2014.904047

McCroskey, J. C. (1982). An introduction to rhetorical communication (4th ed.). Englewood Cliffs, NJ: Prentice Hall.

McCroskey, J. C., Booth-Butterfield, S., \& Payne, S. K. (1989). The impact of communication apprehension on college student retention and success. Communication Quarterly, 37(2), 100-107. https://doi.org/10.1080/ 01463378909385531

Misra, R., \& McKean, M. (2000). College students' academic stress and its relation to their anxiety, time management, and leisure satisfaction. American Journal of Health Studies, 16(1), 41-51. Retrieved December 15, 2018, from http://proxy.lib.utk.edu:90/login?url=https://search.proquest .com/docview/210480531?accountid=14766

National Science Foundation. (2011). Women, minorities, and persons with disabilities in science and engineering: 2011 (NSF 11309), Arlington, VA. Retrieved May 22, 2018, from www.nsf.gov/statistics/wmpd

Papanastasiou, E. C. (2005). Factor structure of the "attitudes toward research" scale. Statistics Education Research Journal, 4(1), 16-26. https://doi.org/10.1037/t64085-000

Papanastasiou, E. C., \& Zembylas, M. (2008). Anxiety in undergraduate research methods courses: Its nature and implications. International Journal of Research and Method in Education, 31(2), 155-167. https:// doi.org/10.1080/17437270802124616

Pekrun, R. (1992). The impact of emotions on learning and achievement: Towards a theory of cognitive/motivational mediators. Applied Psychology, 41(4), 359-376. https://doi.org/10.1111/j.1464-0597.1992 tb00712x

Pekrun, R. (2006). The control-value theory of achievement emotions: Assumptions, corollaries, and implications for educational research and practice. Educational Psychology Review, 18(4), 315-341. https://doi .org/10.1007/s10648-006-9029-9

Pekrun, R., Frenzel, A. C., Goetz, T., \& Perry, R. P. (2007). The control-value theory of achievement emotions: An integrative approach to emotions in education. In Schutz, P., \& Pekrun, R. (Eds.), Emotion in education (pp. 13-36). Amsterdam: Academic.

Pekrun, R., \& Linnenbrink-Garcia, L. (2012). Academic emotions and student engagement. In Christenson, S. L. (Ed.), Handbook of research on student engagement (pp. 259-282). New York: Springer Science+Business Media.

Pekrun, R. P., \& Stephens, E. J. (2010). Achievement emotions in higher education. In Smart, J. C. (Ed.), Higher education: Handbook of theory and research (pp. 257-306). New York: Springer.

Pintrich, P. R., Smith, D. A. F., Garcia, T., \& McKeachie, W. J. (1991). A manual for the use of the Motivated Strategies for Learning Questionnaire. Ann Arbor, MI: National Center for Research to Improve Postsecondary
Teaching and Learning, University of Michigan. Retrieved August 1, 2016, from https://files.eric.ed.gov/fulltext/ED338122.pdf

President's Council of Advisors on Science and Technology. (2012). Engage to excel: Producing one million additional college graduates with degrees in science, technology, engineering, and mathematics. Washington, DC: U.S. Government Office of Science and Technology. Retrieved June 17, 2016, from www.whitehouse.gov/administration/eop/ostp/ pcast/docsreports

R Core Team. (2018). R: A language and environment for statistical computing. Vienna, Austria: R Foundation for Statistical Computing. Retrieved September 1, 2018, from www.R-project.org

Respondek, L., Seufert, T., Stupinsky, R., \& Nett, U. E. (2017). Perceived academic control and academic emotions predict undergraduate university student success: Examining effects on dropout intention and achievement. Frontiers in Psychology, 8, ar243. https://doi.org/10.3389/ fpsyg.2017.00243

Richardson, M., Abraham, C., \& Bond, R. (2012). Psychological correlates of university students' academic performance: A systematic review and meta-analysis. Psychological Bulletin, 138(2), 353-387. https://doi org/10.1037/a0026838

Rocca, K. A. (2010). Student participation in the college classroom: An extended multidisciplinary literature review. Communication Education, 59(2), 185-213. https://doi.org/10.1080/03634520903505936

Shields, N. (2001). Stress, active coping, and academic performance among persisting and nonpersisting college students. Journal of Applied Biobehavioral Research, 6(2), 65-81. https://doi.org/10.1111/j.1751 -9861.2001.tb00107.x

Springer, L., Stanne, M. E., \& Donovan, S. S. (1999). Effects of small-group learning on undergraduates in science, mathematics, engineering, and technology: A meta-analysis. Review of Educational Research, 69(1) 21-51.

Steele, C. M., \& Aronson, J. (1995). Stereotype threat and the intellectual test performance of African Americans. Journal of Personality and Social Psychology, 69(5), 797-811.

Steele, C. M., Spencer, S.J., \& Aronson, J. (2002). Contending with group image: The psychology of stereotype and social identity threat. Advances in Experimental Social Psychology, 34, 379-440. https://doi.org/10.1016/ S0065-2601(02)80009-0

Theobald, E. (2018). Students are rarely independent: When, why, and how to use random effects in discipline-based education research. CBE-Life Sciences Education, 17(3), rm2. https://doi.org/10.1187/cbe.17-12-0280

Wigfield, A., \& Eccles, J. S. (2000). Expectancy-value theory of achievement motivation. Contemporary Educational Psychology, 25, 68-81. https:// doi.org/10.1006/ceps.1999.1015

Witt, P. L., Schrodt, P., Wheeless, V. E., \& Bryand, M. C. (2014). Students' intent to persist in college: Moderating the negative effects of receiver apprehension with instructor credibility and nonverbal immediacy. Communication Studies, 65(3), 330-352. https://doi.org/10.1080/10510974 2013.811428

Yerkes, R. M., \& Dodson, J. D. (1908). The relationship of strength of stimulus to rapidity of habit formation. Journal of Comparative Neurology and Psychology, 18(5), 459-482. https://doi.org/10.1002/cne.920180503

Zeidner, M., \& Matthews, G. (2005). Evaluation anxiety: Current theory and research. In Elliot, A. J. \& Dweck, C. S. (Eds.), Handbook of competence and motivation (pp. 141-166). New York: Guilford.

Zusho, A., Pintrich, P. R., \& Coppola, B. (2003). Skill and will: The role of motivation and cognition in the learning of college chemistry. International Journal of Science Education, 25(9), 1081-1094. https://doi .org/10.1080/0950069032000052207 